\title{
Continuum Damage Modeling of Hydraulic Fracture from Perforations in Horizontal Wells
}

\author{
Feng Sun $(\mathbb{D}$, Peng Jia, and Shifeng Xue \\ College of Pipeline and Civil Engineering, China University of Petroleum, Qingdao, China \\ Correspondence should be addressed to Feng Sun; upcsfeng@upc.edu.cn
}

Received 19 January 2019; Accepted 9 May 2019; Published 27 May 2019

Academic Editor: Daniela Addessi

Copyright (C) 2019 Feng Sun et al. This is an open access article distributed under the Creative Commons Attribution License, which permits unrestricted use, distribution, and reproduction in any medium, provided the original work is properly cited.

\begin{abstract}
The perforations play an important role in determining the near-wellbore fracture geometry during the stimulation phase. To address the impact of perforations on fracture geometry in horizontal wells, a 3D coupled hydromechanical finite element model is developed and employed. Based on the theory of continuum damage mechanics, scalar damage variable governs the degradation of the stiffness of the solid. Damage affects the crack element modeling that is used to consider crack behavior and construct a crack-tracking algorithm to simulate propagation. The model was validated against the analytical solutions and perforation fracture experiments. The results indicate that perforation can be used to control the fracturing pressure and propagation behavior of the initial fracture, which has a further effect on the fracture geometry of near-wellbore region in horizontal wells. Optimizing perforation parameters can direct the propagation of the initial fracture toward the preferred fracture plane. The results demonstrate an improved capability to depict the 3D near-wellbore fracture geometry and fracture propagation with a continuum damage model. The model enables the optimization of orientations and perforation parameters, so that most efficient perforating completions can be designed for hydraulic fracture stimulation.
\end{abstract}

\section{Introduction}

Horizontal drilling and multiple-fracture completions of horizontal wells are effective techniques used today to extract hydrocarbons economically from unconventional reservoirs (shale oil, shale gas, tight gas) $[1,2]$. Perforations provide the fluid conduit between the horizontal wellbore and the formation. The choice of perforation parameters, such as shot density, shot phasing, interval length, and gun orientation, has a significant effect on the geometry of the hydraulic fracture [3-6]. Optimized perforation numbers and location lead to significant improvements in well performance $[7,8]$.

To improve hydraulic fracturing efficiency, the perforation tunnel is suggested to align with the preferred fracture plane to reduce the tortuosity of near-wellbore zone [9]. The oriented perforation technique is used to minimize flow restrictions and friction pressures during fracturing for vertical wellbores. The fracture tortuosity in near wellbore of the horizontal well is undesirable, as they increase the average treating pressure and potentially impact the wellboreto-fracture connectivity during production [10].
Gaining a better understanding of fracture initiation and propagation from perforations is essential for efficient hydraulic fracture treatment. Many researchers have analyzed the stress state near the well and perforation with different analytical and numerical modeling approaches. For the analytic approaches [11, 12], the wellbore and perforation cavities are treated separately, each being considered as an infinitely long cylinder. These cylinders are considered elastic and they are loaded with identical internal pressures. The stress state of a perforation is derived by summing the results of two subproblems of pressurized hollow cylinders. Numerical approaches have been applied to analyze the complicated stressed-state of the perforated wellbore and the fracture-initiation process in 3D. The boundary element method (BEM) was employed to investigate the problem of fracture initiation and perforation failure, and 3D models were built to evaluate the fracture-initiation pressure and predict the location and direction of the initial crack [1315]. The dual boundary element method was employed to investigate the $3 \mathrm{D}$ nonplanar fractures evolution from a cavity [16].The finite element method (FEM) was used to 
obtain the 3D stress state around the horizontal wellbore by considering the completion process, and postfailure behavior model was adopted to simulate fracture propagation [17]. The 3D lattice based method (DEM) was employed to simulate complex hydraulic fracture initiation from perforation and the fracture development process [18].

The above numerical models have mainly focused on predicting the location and direction of initial crack. They rarely provide information on fracture propagation and coalescence among multiple perforations. In this study, a continuum damage mechanics (CDM) based constitutive model has been developed to accurately compute the coupled hydromechanical stress state near the perforation and wellbore and predict complex fracture geometry due to damage (initiation, propagation and coalescence of fractures) in the $3 \mathrm{D}$ problem statement. The FEM modeling approach developed in this paper was validated against the results of analytical solutions and perforation fracture experiments. The fracture-initiation pressure of this paper agrees well with the field-measured data. The visualization of complex fracture growth near a wellbore allows one to comprehend the physical process and optimize the perforation strategy.

\section{The Governing Equations}

To address the impact of perforations on hydraulic fracture initiation and complexity in horizontal wells, numerical simulation of the complicated near-well fracturing process is implemented in two parts. The first part mainly accounts for the fully coupled process of hydraulic fracturing in nearwell region, i.e., the interaction between fluid flow and deformation (fracture), based on poroelasticity [19-22]. The second part accounts for postfailure behavior modeling, such as fracture propagation and coalescence, based on the continuum damage mechanics $[23,24]$.

2.1. Coupled Hydromechanical Models. Based on the theory of poroelasticity [25], the equilibrium equation of porous media with fluid saturated can be expressed as

$$
\sigma_{i j, j}+f_{i}=\sigma_{i j, j}^{\prime}-\alpha p_{, i}+f_{i}=0
$$

Combined with the constitutive relationship of Hooke's law, the elastic deformation equation of rock is obtained as

$$
\frac{E}{2(1+\nu)} u_{i, j j}+\frac{E}{2(1+\nu)(1-2 \nu)} u_{j, j i}-\alpha p_{, i}+f_{i}=0
$$

where $\sigma_{i j}$ is the stress tensor, $\mathrm{Pa} ; \sigma_{i j}^{\prime}$ is the effective stress tensor, $\mathrm{Pa}$; tension is taken as positive; $f_{i}$ is the body force in solid skeleton; $\alpha$ is the Biot coefficient; $p$ is pore pressure, $\mathrm{Pa}$; $u$ is displacement, $\mathrm{m}$; $E$ is Young's modulus, GPa; $v$ is Poisson's ratio.

The mass balance equation of fluid flow in deformable porous media is written as

$$
S \frac{\partial p}{\partial t}-\nabla \cdot q+\alpha \frac{\partial \varepsilon_{\mathrm{v}}}{\partial t}=Q_{f}
$$

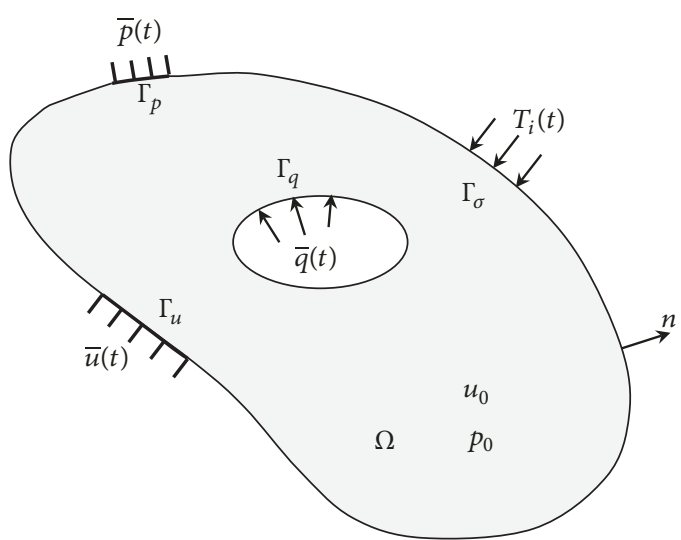

FIgURE 1: Schematic of the problem domain.

According to Darcy's law for fluid flow, the flow rate $q$ is described as

$$
q=-\frac{k}{\mu}\left(\nabla p+\rho_{f} g \nabla Z\right)
$$

where $S$ is the storage coefficient, $\mathrm{Pa}^{-1} ; \varepsilon_{\mathrm{v}}$ is the volumetric strain of rock mass; $Q_{f}$ is the source-sink term of the seepage process, $\mathrm{s}^{-1} ; k$ is rock permeability, $\mu \mathrm{m}^{2} ; \mu$ is fluid viscosity, $\mathrm{Pa} \bullet \mathrm{s} ; \rho_{f}$ is fluid density, $\mathrm{kg} / \mathrm{m}^{3} ; Z$ is elevation, $\mathrm{m}$.

Domain of the problem is illustrated as in Figure 1. Consider a porous continuum in the domain $\Omega$ bounded by surface $\Gamma$, the initial conditions and boundary conditions are stated as follows.

(i) Initial conditions

$$
\begin{gathered}
u_{i}(0)=u_{0}, \\
p(0)=p_{0}
\end{gathered}
$$

in $\Omega$

(ii) Boundary conditions

$$
\begin{array}{rlr}
u_{i} & =\bar{u}(t) \quad \text { on } \Gamma_{u} \\
\sigma_{i j} \cdot n & =T_{i}(t) \quad \text { on } \Gamma_{\sigma} \\
p & =\bar{p}(t) \quad \text { on } \Gamma_{p} \\
-\frac{k}{\mu} \nabla p & =\bar{q}(t) \quad \text { on } \Gamma_{q}
\end{array}
$$

where $u_{0}, p_{0}$ are the displacement and pressure of initial domain, $\bar{u}(t), \bar{p}(t)$ are the displacement and pressure of boundary, $T_{i}(t)$ is the boundary force, $n$ is the unit normal vector perpendicular to the boundary surface, $\bar{q}(t)$ is the fluid flux, $\Gamma_{u}, \Gamma_{\sigma}, \Gamma_{p}$, and $\Gamma_{q}$ are the bound surface of the displacement, stress, pore pressure, and flux, respectively.

2.2. Continuum Damage Evolution. During hydraulic fracturing process, the damage mechanisms in porous rocks are categorized based upon stress state, hydraulic pressure, 
and environmental conditions. The maximum tensile stress criterion is used for the determination of the location and direction of the initial crack $[11,13]$.

$$
F\left(\sigma_{1}\right)=\sigma_{1}-f_{t 0}
$$

where $F\left(\sigma_{1}\right)$ is the yield function of tensile failure, $\mathrm{Pa} ; \sigma_{1}$ is the maximum principal stress, $\mathrm{Pa} ; f_{t 0}$ is the tensile strength of rock, $\mathrm{Pa}$.

The stress distribution, hydraulic fracture initiation, and propagation of perforation tips and near wellbore are analyzed, based on the failure element concept. When the stress components are obtained, the fracture-initiation criterion (7) can recognize the failure point in the scale of element level. In continuum damage mechanics (CDM), damage can be considered as a macroscopic state variable that affects stiffness degradation of the material and can be used to modify the stiffness matrix for a failure element.

Information on failure element, time, and position is recorded in a dataset at each time step. Based on the damage mechanics theory, the Young's modulus of the element degrades gradually during damage progress [23], and the damage evolution law of the damaged element is defined as follows:

$$
E=(1-D) E_{0}
$$

where $E$ and $E_{0}$ represent the Young's modulus of the damaged elements and undamaged elements and $D$ is the damage variable.

Damage evolution of the element in tensional state can be expressed as [26]

$$
D= \begin{cases}0 & \varepsilon_{t}<\varepsilon_{t 0} \\ 1-\frac{\lambda \varepsilon_{t 0}}{\varepsilon_{t}} & \varepsilon_{t} \geq \varepsilon_{t 0}\end{cases}
$$

where $\varepsilon_{t}=\sqrt{\sum_{i=1}^{3}\left(\left(\left|\varepsilon_{i}\right|+\varepsilon_{i}\right) / 2\right)^{2}}$ is the equivalent principal strain for a tensile state, $\varepsilon_{i}(i=1,2,3)$ are the three principal strains, $\varepsilon_{t 0}$ is the elastic limit of tensile strain, $\lambda$ is the residual strength coefficient.

Considering the continuum damage evolution, the constitutive equation (2) can be further written as

$$
\frac{E(1-D)}{2(1+\nu)} u_{i, j j}+\frac{E(1-D)}{2(1+\nu)(1-2 \nu)} u_{j, j i}-\alpha p_{, i}+f_{i}=0
$$

Because of the damage, permeability is correlated to damage effect within the failure elements. The permeability can be described as [23]:

$$
k=\xi k_{0} \exp \left(-\eta \bar{\sigma}^{\prime}\right) \quad 0<D \leq 1
$$

where $k_{0}$ is the initial permeability, $\eta$ is a coupling coefficient, $\bar{\sigma}^{\prime}$ is the effective average stress, $\xi$ is the mutation coefficient, which reflects the permeability mutation in the damage element.

\section{Numerical Solution}

3.1. Finite Element Formulations. Using the Galerkin weighted residual method and the Green-Gauss theorem [27], the force equilibrium equation (1) and the continuity equation for fluid flow (3) can be converted into the matrix form after finite element discretization:

$$
\begin{array}{r}
{[\mathbf{K}] \mathbf{u}+[\mathbf{Q}] \mathbf{p}=\mathbf{f}^{u}} \\
{[\mathbf{S}] \dot{\mathbf{p}}+[\mathbf{H}] \mathbf{p}+\left[\mathbf{Q}^{\mathrm{T}}\right] \dot{\mathbf{u}}=\mathbf{f}^{q}}
\end{array}
$$

where $\mathbf{u}, \mathbf{p}$ are the vectors of displacement and pressure and $\dot{\mathbf{u}}$, $\dot{\mathbf{p}}$ are corresponding time derivatives. The matrix expressions are listed as follows.

$$
\begin{aligned}
\mathbf{K} & =\int_{\Omega} \mathbf{B}^{\mathrm{T}} \mathbf{D} \mathbf{B} d \Omega \\
\mathbf{Q} & =\int_{\Omega} \alpha \mathbf{B}^{\mathrm{T}} \mathbf{m}_{p} d \Omega \\
\mathbf{f}^{u} & =\int_{\Omega} \mathbf{N}_{u}^{\mathrm{T}} \mathbf{f} d \Omega+\int_{\Gamma_{\sigma}} \mathbf{N}_{u}^{\mathrm{T}} \mathbf{T} d \Gamma \\
\mathbf{S} & =\int_{\Omega} \mathbf{N}_{p}^{\mathrm{T}} S \mathbf{N}_{p} d \Omega \\
\mathbf{H} & =\int_{\Omega} \nabla \mathbf{N}_{p}^{\mathrm{T}} \frac{k}{u} \nabla \mathbf{N}_{p} d \Omega \\
\mathbf{f}^{p} & =\int_{\Gamma_{q}^{e}}-\mathbf{N}_{p}^{\mathrm{T}} \bar{q} d \Gamma
\end{aligned}
$$

In order to integrate equation (13) with respect to time, the linear interpolation in time can be discretized with standard finite difference methods, and the incremental forms of the above FE equations can be written as

$$
\begin{aligned}
{[\mathbf{K}] \mathbf{u}_{t+\Delta t}=} & {[\mathbf{K}] \mathbf{u}_{t}+[\mathbf{Q}] \Delta \mathbf{p}_{t}+\Delta \mathbf{f}^{u} } \\
{[\mathbf{S}+\theta \Delta t \mathbf{H}] \mathbf{p}_{t+\Delta t}=} & {[\mathbf{S}-(1-\theta) \Delta t \mathbf{H}] \mathbf{p}_{t}-\left[\mathbf{Q}^{\mathrm{T}}\right] \Delta \mathbf{u}_{t} } \\
& +\Delta t \mathbf{f}^{q}
\end{aligned}
$$

where $\mathbf{u}_{t+\Delta t}, \mathbf{p}_{t+\Delta t}$ represent the solution at the current time step, $\mathbf{u}_{t}, \mathbf{p}_{t}$ is the solution at last time step, $\theta$ is an integration parameter in the interval $0 \leq \theta \leq 1$. In the following numerical example, we choose $\theta=1$.

The displacement convergence criterion is used to judge the convergence of incremental solution

$$
\triangle \varepsilon=\sum_{i=1}^{\text {node }} \frac{\triangle u_{t}^{2}}{u_{t}^{2}} \leq 10^{-5}
$$

where $\triangle \mathcal{\varepsilon}$ is the iterative tolerance of the displacement increment, $\Delta u_{t}=u_{t+\Delta t}-u_{t}$ is the displacement increment at current time step, and $u_{t}$ is the displacement at last time step.

3.2. Computational Procedures. Using FEPG software as a platform, an incremental finite element procedure is developed using the continuum damage evolution criteria, and 
the iterative decoupling method is used to solve the above equations of geomechanics and reservoir flow variables.

Given a set of initial values, the fluid pressure $p$ is computed first from (16). Then the displacement, strain, and stress are computed from (15) from updated $p$ and boundary conditions. The coupling iteration is controlled by a convergence criterion, which is based on (17).

With loading history changing, the stress concentration region gradually reaches the fracture-initiation criterion (7). Then, this region's elements are defined as damage elements. The damage elements' matrices $\mathbf{K}$ and $\mathbf{H}$ are determined using (9) and (11). In this way, the initiation and growth of fracture can be described using continuum damage mechanics. The flow chart of the iteration process is shown in Figure 2.

3.3. Verification of the Solution Algorithm. The coupled hydromechanical solution algorithm is verified against the Terzaghi's consolidation problem $[28,29]$. This problem consists of a fluid-saturated column of soil layer with loading $p_{0}$ on top. Drainage is only allowed through the top surface of the soil column. Figure 3 shows the geometry and boundary conditions of this problem, and the load is applied instantaneously at time $t=0$. For solution algorithm verification, we choose Youth's modulus $E=1.0 \mathrm{GPa}$, Possion's ration $\nu=0.25$, permeability $k=1.0 \mathrm{um}^{2}$, fluid viscosity $\mu=1.0 \times 10^{-3} \mathrm{~Pa} \bullet \mathrm{s}$, Biot coefficient $\alpha=1.0$, and initial pressure $p_{0}=1.0 \mathrm{MPa}$.

As is shown in Figure 4, a good matching between the analytical solution $[28,29]$ and the numerical result is obtained for both pore pressure along the vertical direction at different time and vertical displacement at the top versus time.

\section{Computational Model and Validations}

4.1. Model Configuration. Field examples of horizontal wells in Changqing oilfield (Xi'an, China) are introduced. Numerical simulations have been performed to analyze the developed fracture geometry for traditional spiral perforation and in-plane perforation in a horizontal well. The numerical results were compared with analytical solutions and experimental geometry.

The wellbore is assumed to be located at the center of a block of $3.0 \mathrm{~m} \times 5.0 \mathrm{~m} \times 5.0 \mathrm{~m}$ dimensions, and the nearwellbore block of $1.0 \mathrm{~m} \times 1.5 \mathrm{~m} \times 1.5 \mathrm{~m}$ is selected to local encryption of element mesh. The horizontal borehole axis aligned with the minimum horizontal stress $\sigma_{\mathrm{h}}$ direction. The model has one perforation cluster, which includes six perforation tunnels, and the phase angle of perforation tunnels is $60^{\circ}$. We assume the direction of two middle perforations is consistent with the maximum horizontal stress $\sigma_{\mathrm{H}}$. The perforation tunnel length is $400 \mathrm{~mm}$, and the diameter of perforation tunnel is $20 \mathrm{~mm}$.

The applied far-field in-situ stresses: vertical stress $\sigma_{\mathrm{v}}=43.0 \mathrm{MPa}$, maximum horizontal stress $\sigma_{\mathrm{H}}=38.0 \mathrm{MPa}$, and minimum horizontal stress $\sigma_{\mathrm{h}}=34.0 \mathrm{MPa}$ are applied on three sides, as shown in Figure 5(a). The other three sides of the model are applied as roller boundary conditions. For fluid phase, the pore pressure of the reservoir $p=18.0 \mathrm{MPa}$ is

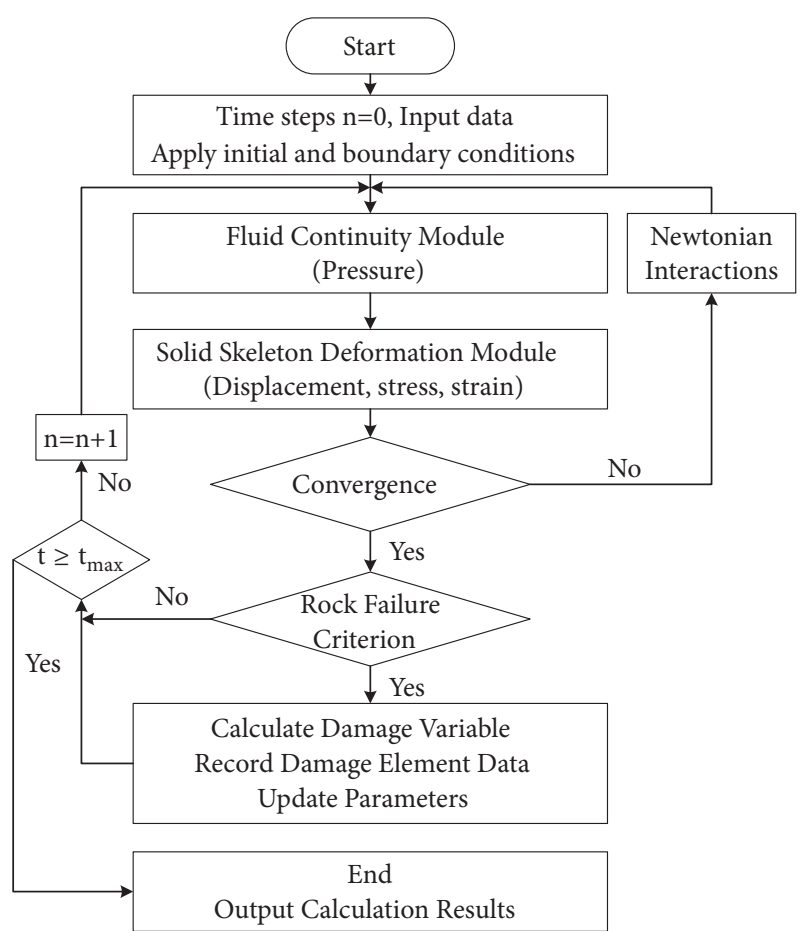

FIGURE 2: Flow chart of the iterative calculations in coupled FE model.

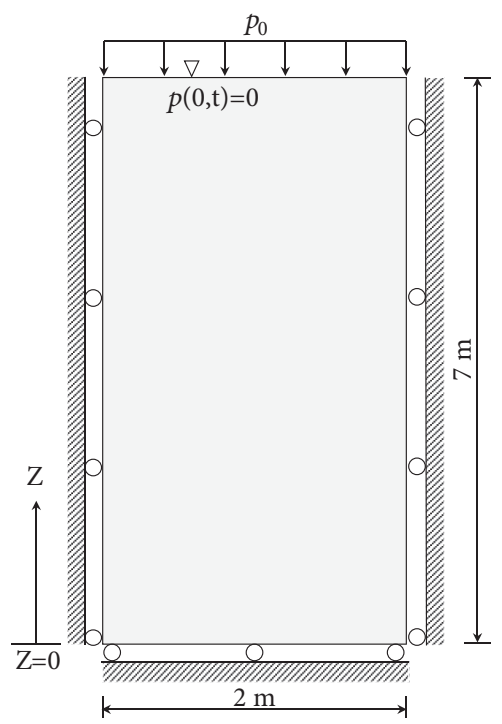

FIGURE 3: Geometry for Terzaghi's consolidation problem.

applied as the initial condition. No-flow boundary condition is applied on all sides.

For an open-hole horizontal well, it was assumed that the same bottom-hole pressure (BHP) $p_{p}$ loads were applied on the wellbore and perforation surfaces. For a cased horizontal well, the BHP $p_{p}$ acting on the inside of the casing wall is partially transmitted to the rock face, since the stiffness of casing is much higher than the rock. An approximate approach to the evaluation of pressure $p_{\mathrm{w}}$ applied to the 


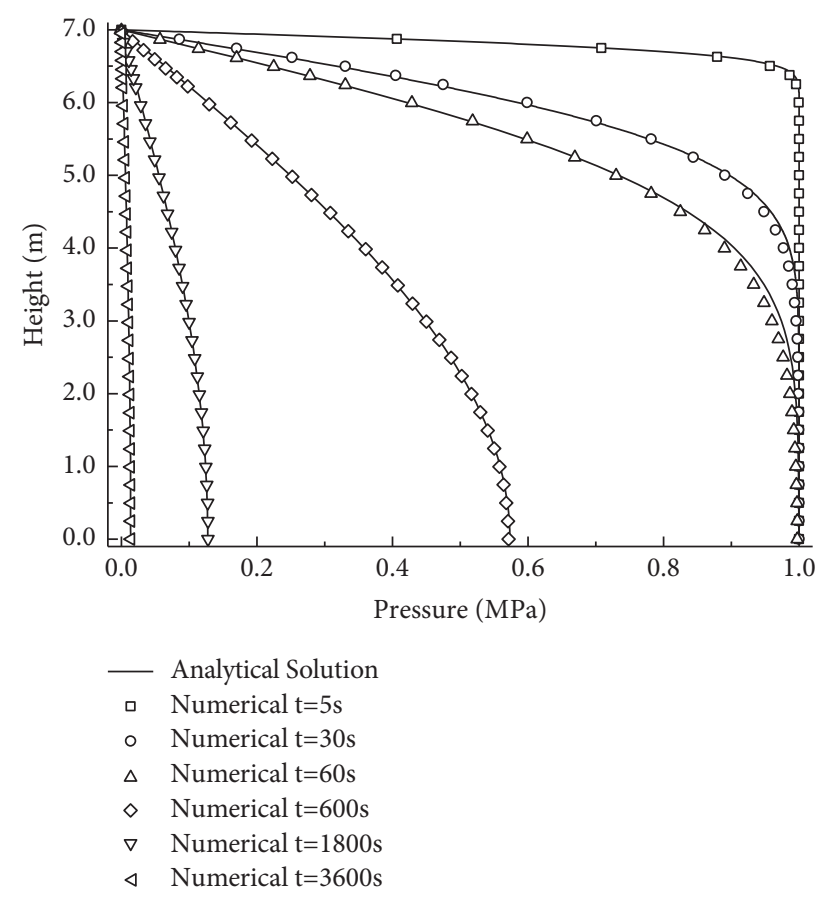

(a)

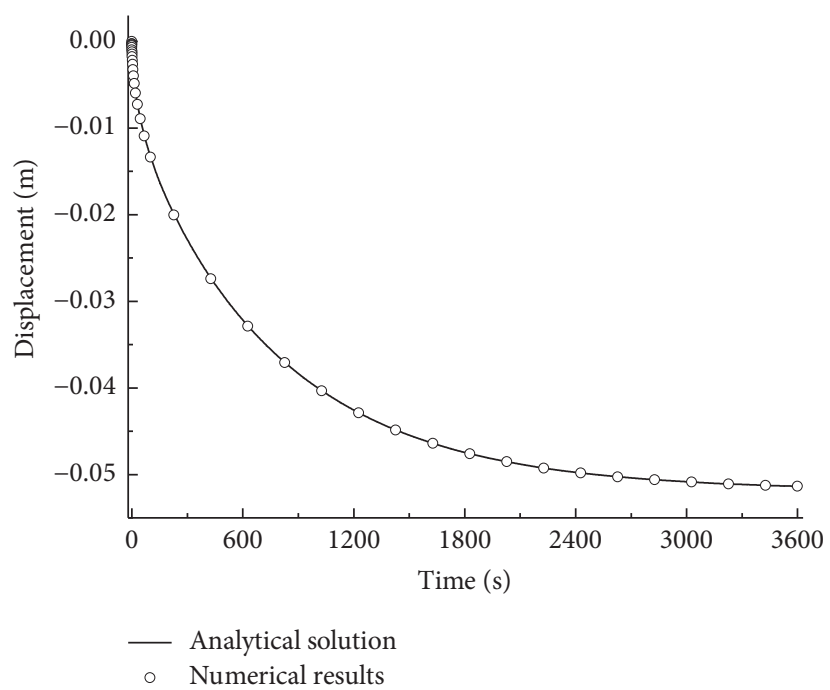

(b)

Figure 4: Comparison of numerical results and analytical solution of Terzaghi's problem. (a) Pore pressure and (b) vertical displacement at the top.

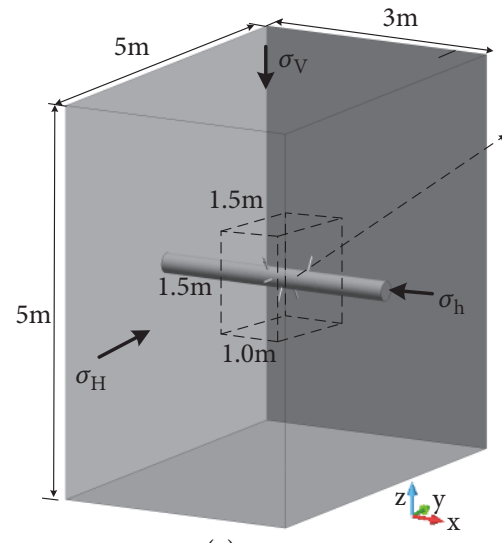

(a)

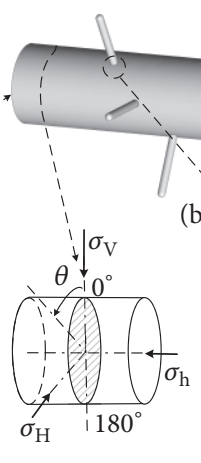

(c)

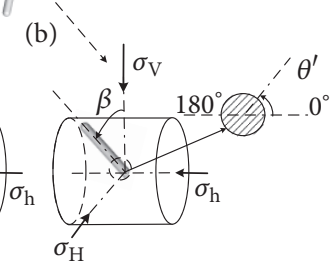

(d)

FiguRE 5: Schematic of the model. (a) Model geometry, (b) spiral perforation model, (c) wellbore angle diagram, and (d) perforation angle diagram.

borehole boundary in a cased-and-cemented wellbore has been proposed $[8,13]$ :

$$
p_{w}=T F\left(p_{p}-c \sigma_{\mathrm{h}}\right)+c \sigma_{\mathrm{h}}
$$

TF

$$
\begin{aligned}
= & \frac{\left(\left(1+v_{s}\right) / E_{s}\right)\left(2\left(1-v_{s}\right) /\left(R_{o}^{2}-R_{i}^{2}\right)\right) R_{i}^{2}}{(1+v) / E+\left(\left(1+v_{s}\right) / E_{s}\right)\left(\left(R_{i}^{2}+\left(1-2 v_{s}\right) R_{o}^{2}\right) /\left(R_{o}^{2}-R_{i}^{2}\right)\right)} \\
& \cdot \frac{R_{o}^{2}}{r_{w}^{2}}
\end{aligned}
$$

where $E_{s}, v_{s}$ are Young's modulus and Poisson's ratio of the steel, $T F$ is the transmission factor, $c$ is the in-situ stress factor, $R_{i}, R_{o}$ are the inner and outer radii of the casing, and $r_{w}$ is the inner radius of wellbore.

The reservoir properties and well parameters are reported in Table 1.

Figure 6 presents a typical field fracturing records of surface injection pressure and injection rate. The increasing injection rate is up to $8.0-11.0 \mathrm{~m}^{3} / \mathrm{min}$. From the pump pressure curve, the average breakdown pressure is $26.9 \mathrm{MPa}$. This data can be converted to the fracture initial pressure $\left(p_{\mathrm{f}}\right)$ of $43.1 \mathrm{MPa}$, with the addition of a hydraulic head of 


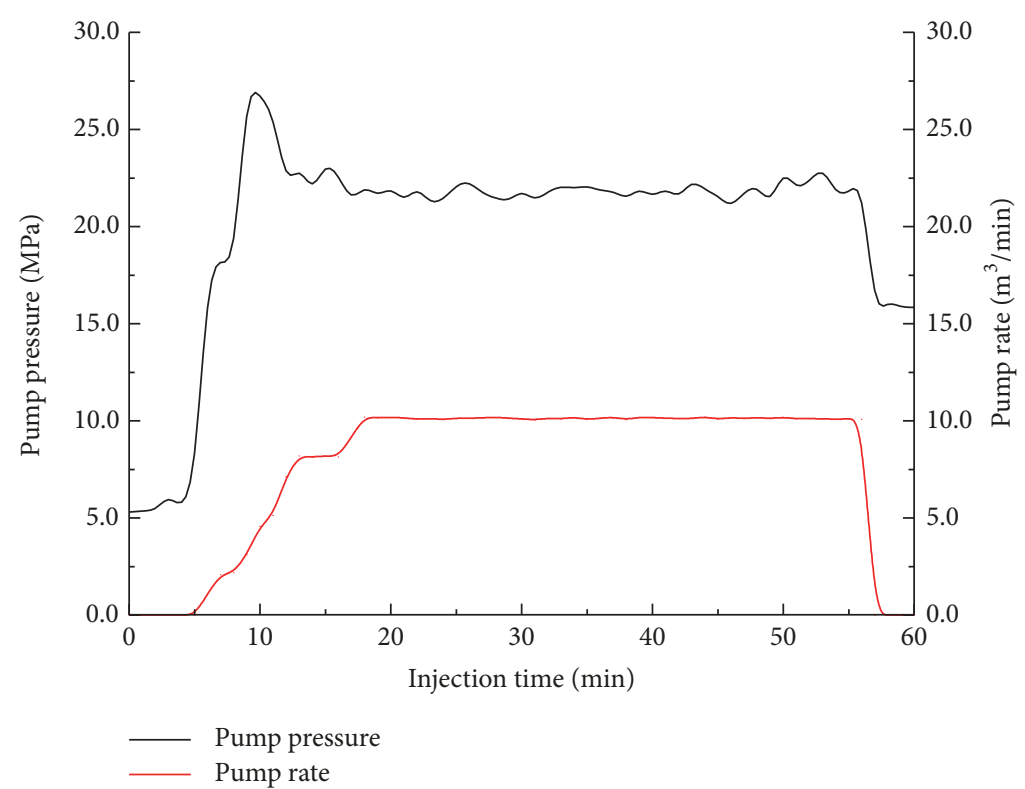

FIGURE 6: Typical fracturing curve of the fracturing treatment.

TABLE 1: Reservoir properties and well parameters.

\begin{tabular}{lc}
\hline Parameters & Values \\
\hline Young's modulus of rock $E_{0}(\mathrm{GPa})$ & 21.5 \\
Poisson's ratio of rock $\nu$ & 0.23 \\
Biot coefficient $\alpha$ & 0.65 \\
Permeability $k\left(\mathrm{~m}^{2}\right)$ & $3.0 \times 10^{-15}$ \\
Tensile strength $f_{t 0}(\mathrm{MPa})$ & 3.0 \\
Residual strength coefficient $\lambda$ & 0.15 \\
Mutation coefficient $\xi$ & 10.0 \\
Coupling coefficient $\eta$ & 0.025 \\
Wellbore diameter $r_{w}(\mathrm{~mm})$ & 178 \\
External diameter of the casing $R_{o}(\mathrm{~mm})$ & 178 \\
Internal diameter of the casing $R_{i}(\mathrm{~mm})$ & 164 \\
Young's modulus of casing $E_{s}(\mathrm{GPa})$ & 210 \\
Poisson's ratio of casing $v_{s}$ & 0.21 \\
In situ stress factor $c$ & 0.3 \\
\hline
\end{tabular}

18.0MPa and the friction loss of almost 1.8 MPa. In this case, a varying pressure boundary condition $\bar{p}(t)$ is applied on the inner face of perforation tunnels and wellbore. According to the field data of Figure 6, the pressurization rate is settled as $0.05 \mathrm{MPa} / \mathrm{s}$ in this case.

4.2. Model Validations. The FEM model was validated against the results of analytical model and perforation fracture experiments. The tangential stress distribution in the openhole horizontal wellbore is shown as Figure 7. We compare the FEM results with the analytical solution (AS) of tangential stress along the wellbore and perforation tunnel [11, 12]. Figure 7 (a) presents that the FEM results are close to the AS results with a difference of less than $3.5 \%$.
Figure 7(b) compares the tangential stress along the perforation tunnel with change of perforation deflection angle $\beta$. For $\beta=0^{\circ}$, the maximum tangential stress is at tangential angle of perforation tunnel $\theta^{\prime}=0^{\circ}$. While for $\beta=90^{\circ}$, the maximum tangential stress is at $\theta^{\prime}=90^{\circ}$. The difference between FEM results and AS solutions of the tangential stress along the perforation tunnel is less than $6.5 \%$.

Figure 8 compares the damage fracture geometry in near wellbore of horizontal well between numerical simulation results and that of the perforation fracture experiments [17]. One can see from the numerical results that fracture extends through each perforation as they spiral around the casing and form the fracture geometry with spiral distortion. The laboratory experiment simulated a horizontal well with the wellbore axis along the minimum stress direction, and the fracture geometry is also spiral around the casing. The above results show that the developed FEM model can be used to analyze the stress and fracture geometry in the near-well region.

\section{Results and Discussions}

5.1. Sensitivity of Fracture Initiation to Perforation Orientation. The effect of perforation orientation on initial fracture geometry is analyzed through various angle $\beta$ relative to the vertical direction.

With the increase of perforation deflection angle, as shown in Figure 9, two possible scenarios of fracture initiation are observed for open-hole perforation horizontal well. With the comparatively small angle $\left(\beta=0^{\circ}, \beta=30^{\circ}\right)$, the zones for rock failure concentrate on the junction site of perforation and the borehole wall. The fracture is along the longitudinal direction of the wellbore (Figures $9(\mathrm{a})$ and $9(\mathrm{~b})$ ). With the increase of the perforation angle $\left(\beta=60^{\circ}, \beta=90^{\circ}\right)$, the initial rupture position is located at the middle and toe 


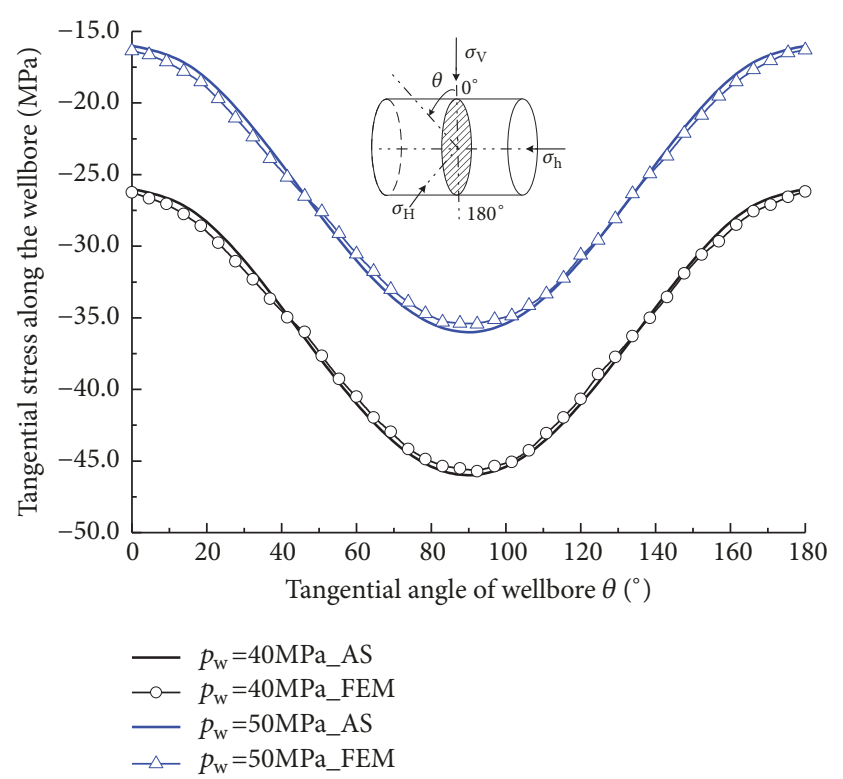

(a)

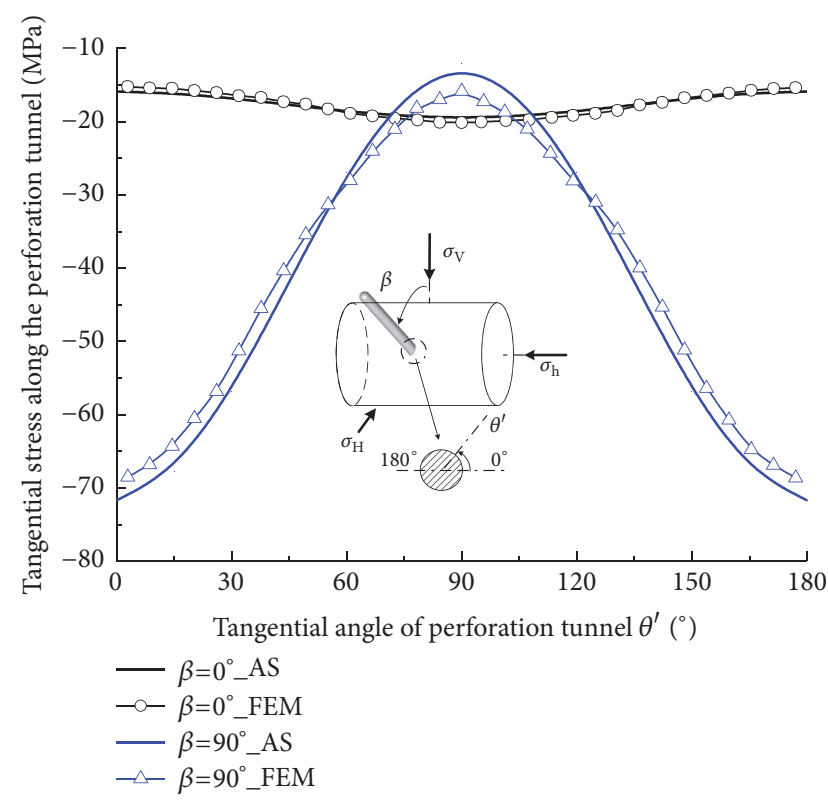

(b)

Figure 7: Comparison of tangential stress in open-hole horizontal well. (a) Tangential stress along the wellbore and (b) tangential stress along the perforation tunnel.

end of the perforation tunnel, forming a transverse rupture perpendicular to the horizontal wellbore axis (Figures $9(\mathrm{c})$ and $9(\mathrm{~d}))$.

For cased-cement horizontal well, the initiated fractures are all transverse to the wellbore (Figure 10). For $\beta \leq 60^{\circ}$, fractures initiate from the perforation base (Figures 10(a), 10(b), and 10(c)). While $\beta$ continues increasing, the initial fracture position is extended from base to the middle and tip of the tunnel (Figure 10(d)).

According to the numerical results, the initiation of the fractures is sensitive to perforation orientation. The change of stress conditions controlling the fractures initiation can explain this phenomenon.

When the perforation angle $\beta=0^{\circ}$, as shown in the computational model (Figure 5(d)), the axis of the tunnel is along the direction of vertical stress $\sigma_{\mathrm{v}}$. The fracture initial pressure of the tunnel is mainly affected by the maximum horizontal stress $\sigma_{\mathrm{H}}$ and minimum horizontal stress $\sigma_{\mathrm{h}}$. As the perforation angle $\beta=90^{\circ}$, the axis of the tunnel is along the direction of the maximum horizontal stress. The fracture initial pressure is dominated by the vertical stress $\sigma_{\mathrm{v}}$ and minimum horizontal stress $\sigma_{\mathrm{h}}$.

As shown in Figure 11, the difference of fracture pressure between open-hole horizontal wells reaches 6.5 MPa. For the case-cement horizontal well, the cementation effect of casing and cement ring reduced the pressure load applied on the near borehole rock [13]. Figure 11 shows that the casing and cement layer result in decrease of the fracture initial pressure 4.0 7.5 MPa than open-hole horizontal well. With the increase of perforation angle $\beta$, the fracture initial pressure $p_{\mathrm{f}}$ grows up to its maximum at $\beta=90^{\circ}$, the $p_{\mathrm{f}}$ difference between various perforation angles for case-cement horizontal well is $3.5 \mathrm{MPa}$.
5.2. The Initial Fracture Characters of Horizontal Wells. Figure 12 presents the maximum stress principal change of spiral perforations during the pressurization period. With the $\mathrm{BHP} p_{p}$ applied on the perforation tunnel reaching $41.5 \mathrm{MPa}$, the maximum principal stress of element on the middle tunnel reaches $3.02 \mathrm{MPa}$ and surpasses the tensile strength of the rock. The initial fracture appears at the interface of wellbore and middle perforation tunnel, leading to fracture perpendicular to the wellbore (Figure 13(a)).

Based on continuum damage mechanics, the failure elements' matrices of stiffness and seepage are updated. The postfailure and growth of fracture can be described by the damage-driven crack element modeling. As $p_{p}$ increases to $43.5 \mathrm{MPa}$, the maximum principal stress on the side perforation tunnels is also beyond the tensile strength and gives initiation of cracks extending along the perforation axis (Figure 13(b)). With the pressure increase, the damaged zone extends and links up among multiperforations (Figure 13(c)).

The stress interference between the spiral perforation channels controls the direction of fracture propagation in local region of perforation, inducing the fracture tortuosity in near wellbore. According to the FEM results, the fracturing pressure of different perforations ranges between $41.5 \mathrm{MPa}$ and $43.5 \mathrm{MPa}$, which is in a good agreement with the field fracturing recording FIP 43.1MPa.

The fracture tortuosity (Figures $8(\mathrm{a})$ and $13(\mathrm{c})$ ) in nearwellbore region of the horizontal well is undesirable, as they increase the average treating pressure and the flow restriction.

The in-plane perforation technique was proposed to change conventional spiral distribution of firing holes and adopt special charge distribution mode for horizontal wells [9]. The in-plane perforation technique designs perforation 


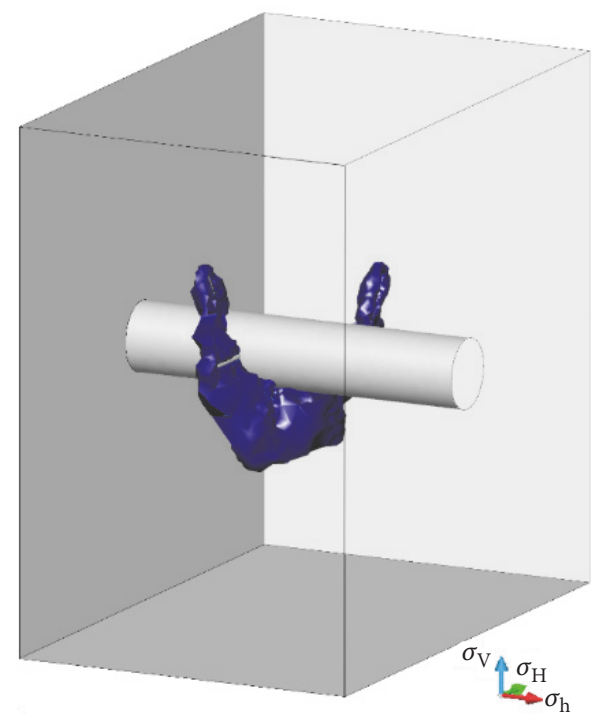

(a)
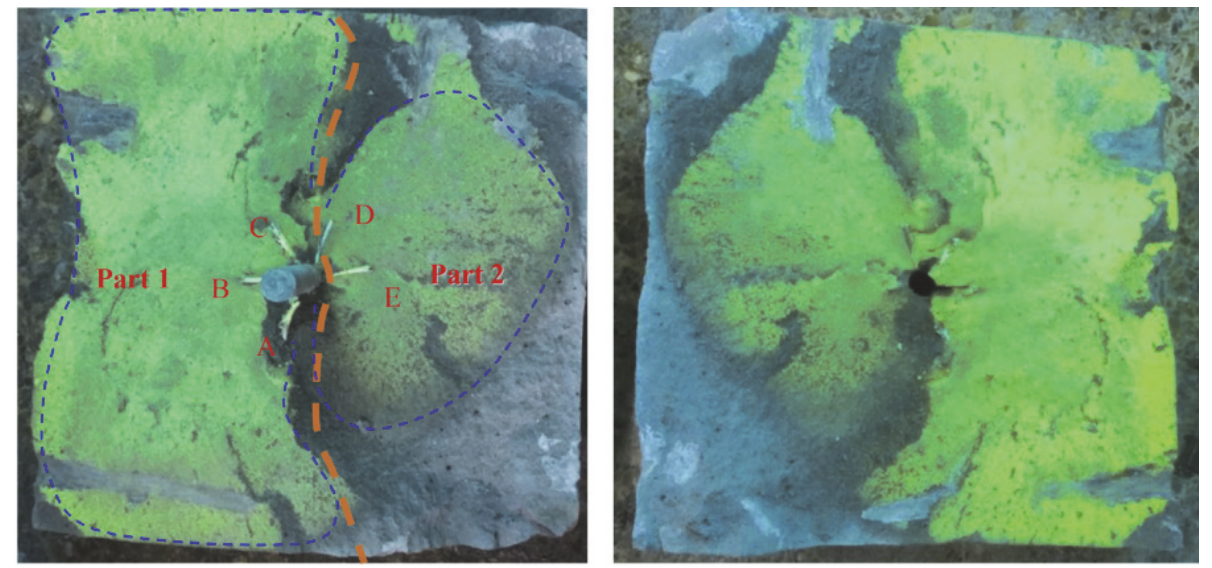

(b)

FIGURE 8: Comparison of fracture geometry in near wellbore of spiral perforation. (a) Fracture geometry in the FEM model and (b) fracture geometry in experiment [17].

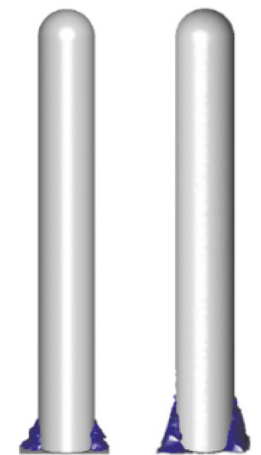

(a)

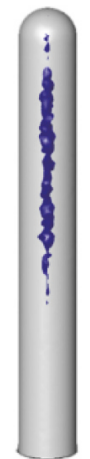

(c)

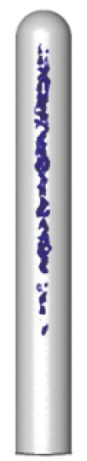

(d)

FIGURE 9: Initial fracture geometry for open-hole perforation with different angle $\beta$. (a) $\beta=0^{\circ}$, (b) $\beta=30^{\circ}$, (c) $\beta=60^{\circ}$, and (d) $\beta=90^{\circ}$. 


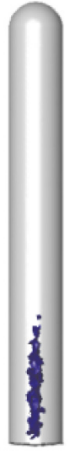

(a)

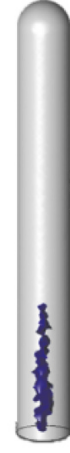

(b)

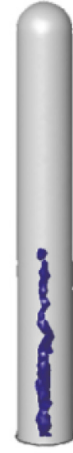

(c)

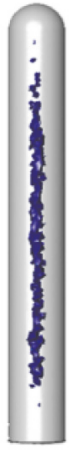

(d)

FIGURE 10: Initial fracture geometry for case-cement perforation with different angle $\beta$. (a) $\beta=0^{\circ}$, (b) $\beta=30^{\circ}$, (c) $\beta=60^{\circ}$, and (d) $\beta=90^{\circ}$.

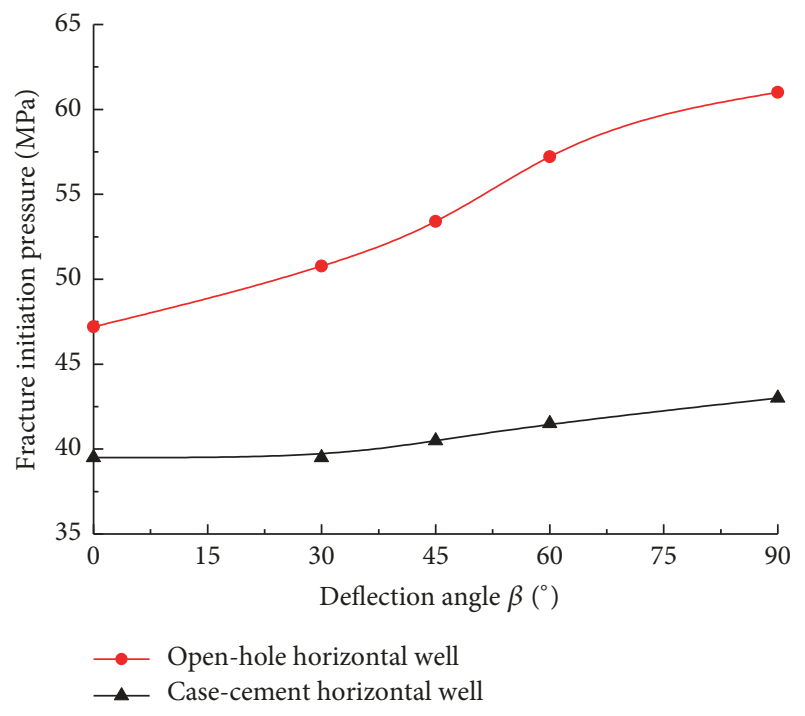

FIGURE 11: Effects of deflection angle on perforation initiation pressure.

axis aiming at the preferred fracture plane, and the stress interference of multiperforations increases.

The maximum principal stress change of in-plane perforation is calculated and shown in Figure 14. In this case, the side perforations incline angle $\gamma$ set as $25^{\circ}$. The maximum principal stress of element on the middle tunnel surpasses the tensile strength of rock at BHP $p_{p}=39.5 \mathrm{MPa}$. This value is 2.0 MPa lower than the conventional spiral perforation case, which helps reduce the FIP of hydraulic fracture. According to the field fracturing recording of Changqing oilfields, the average fracturing pressure for in-plane perforations horizontal wells is $39.2 \mathrm{MPa}$. This data is consistent well with the calculation results of this paper.

By adjusting the tunnel inclined angle $\gamma$, in-plane perforation can also control the initial fracture directions of the perforation. As shown in Figure 15, the fracture of side perforations initiates and extends along the perforation axis, leading to the coalescence of fractures.

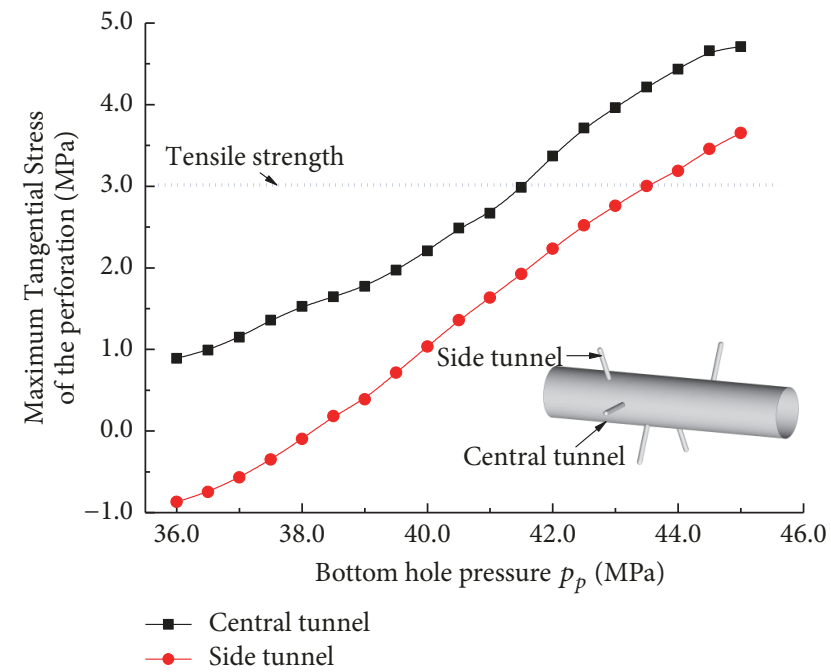

FIGURE 12: The maximum principal stress change of spiral perforation tunnels.

5.3. The Near-Wellbore Fracture Geometry of Horizontal Wells. Figure 16 depicts the damage evolution process around the horizontal wellbore for different perforation strategies. For open-hole horizontal well, the crack of multiperforations extends along the axial and vertical directions of the wellbore and form a complex near-wellbore rupture pattern, as illustrated in Figure 16(a). The fracture geometry of casecement horizontal well is spiral around the casing with spiral distortion (see Figure 16(b)), which increases the average treating pressure and affects the wellbore-to-fracture connectivity.

Figure 16(c) presents the near-wellbore fracture geometry of in-plane perforation horizontal well. The crack extends along the inclined perforation and deflects to the damage zones of the middle tunnels. Two preferred fan shaped fracture plane perpendicular to the axial of the casing. The in-plane perforations guide the initial fracture trajectory toward the preferred transverse fracture plane. This kind 


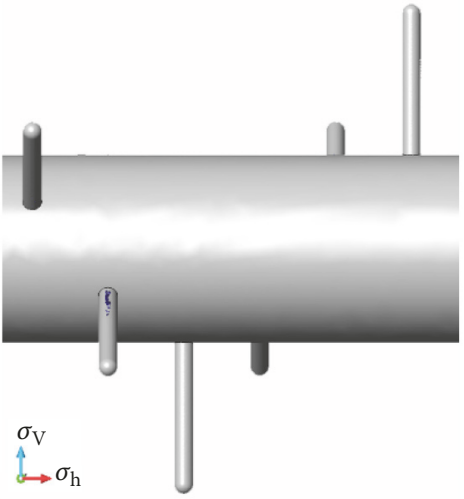

(a)

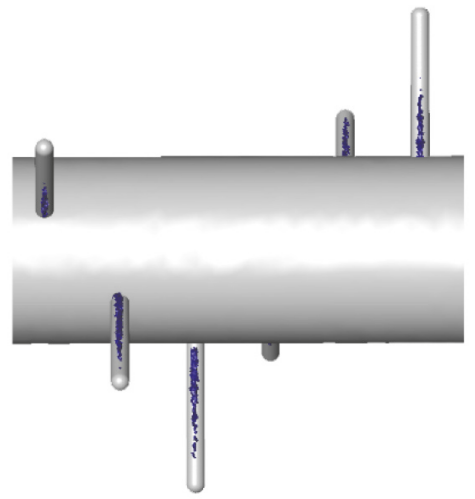

(b)

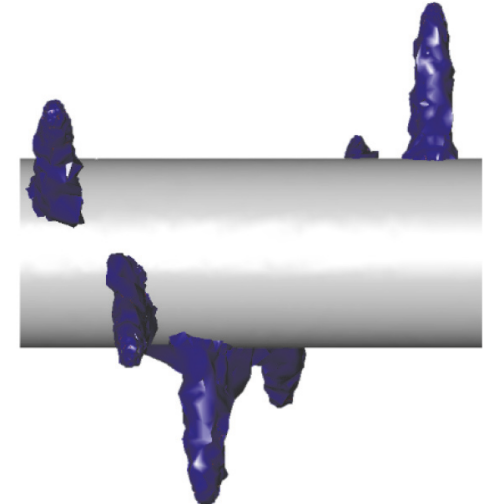

(c)

FIGURE 13: Damage evolution of spiral perforation during the pressurization period. (a) $p_{p}=41.5 \mathrm{MPa}$, (b) $p_{p}=43.5 \mathrm{MPa}$, and (c) $p_{p}=45.0 \mathrm{MPa}$.

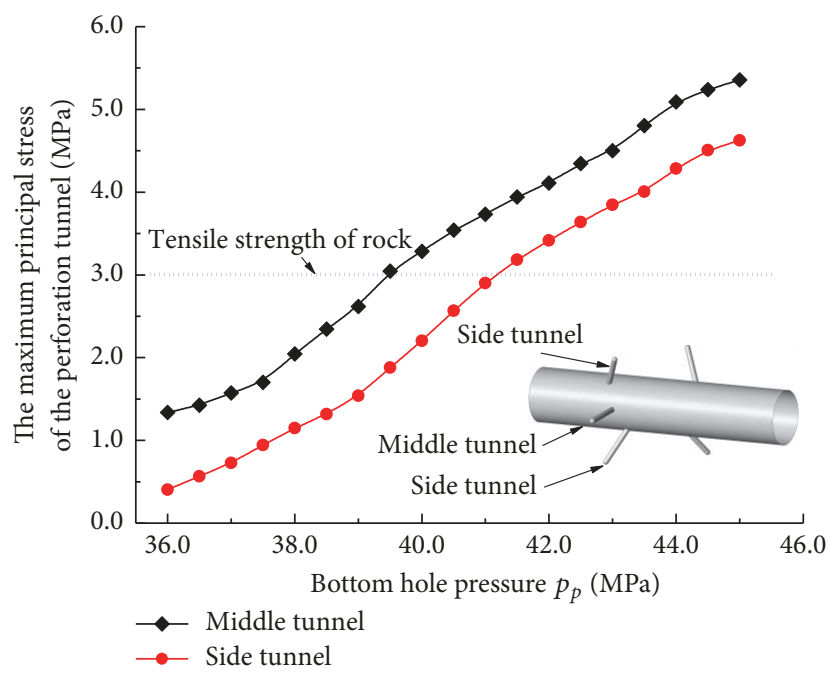

FIGURE 14: The maximum principal stress change of in-plane perforation tunnels.

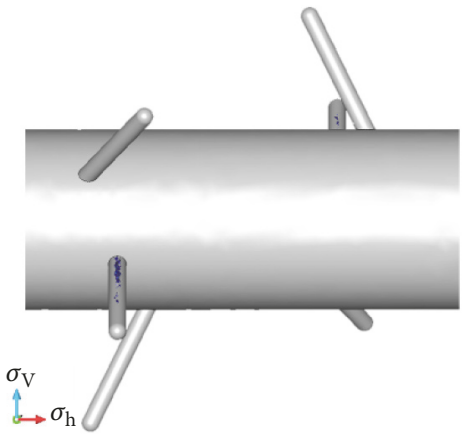

(a)

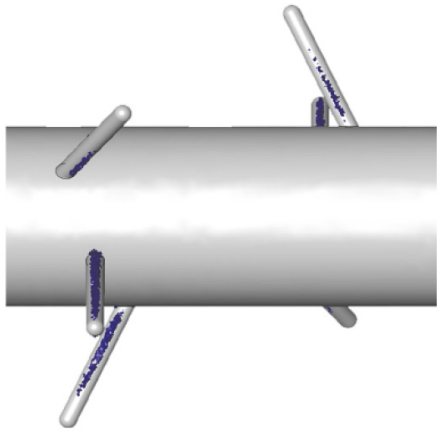

(b)

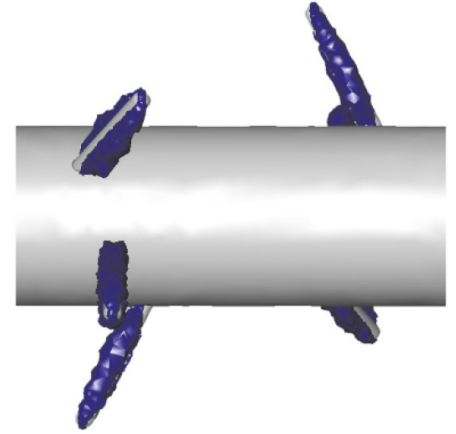

(c)

FIGURE 15: Damage evolution of in-plane perforation during the pressurization period. (a) $p_{p}=39.5 \mathrm{MPa},(\mathrm{b}) p_{p}=41.5 \mathrm{MPa}$, and (c) $p_{p}$ $=45.0 \mathrm{MPa}$. 


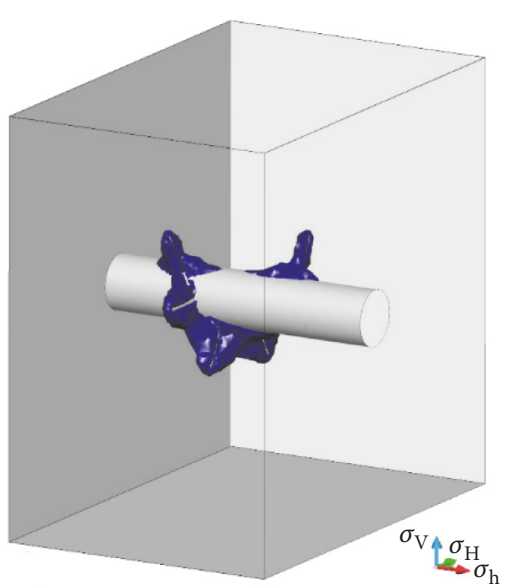

(a)

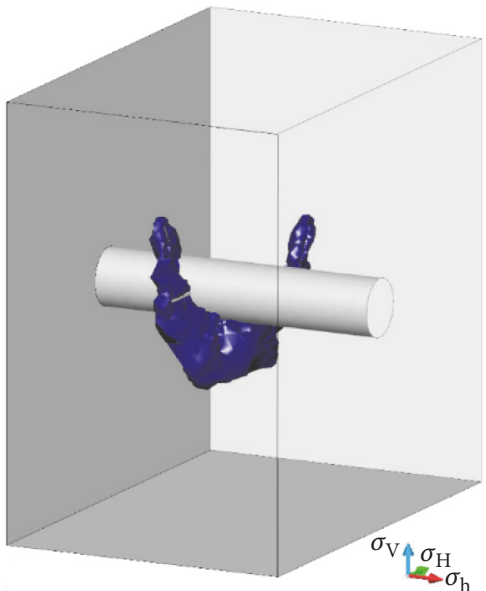

(b)

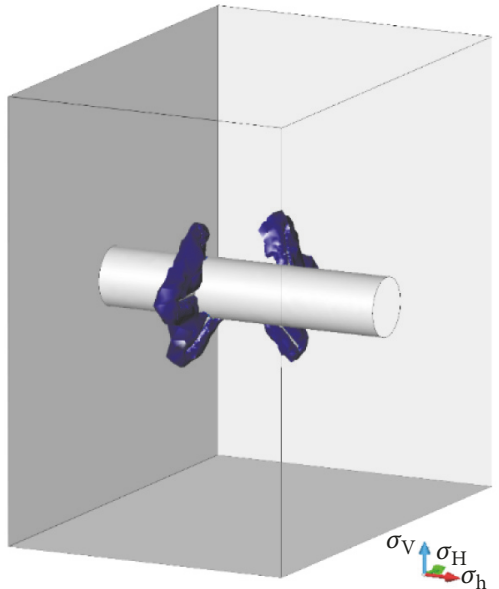

(c)

FIGURE 16: Comparison of near-wellbore fracture geometry with different perforation strategies. (a) Open-hole horizontal well, (b) casecement horizontal well, and (c) in-plane perforation horizontal well.

of fracturing morphology would avoid the tortuous nearwellbore fracture geometry beneficial to wellbore-to-fracture connectivity.

The above sensitivity study performed revealed that perforation is an effective strategy to control the fracturing pressure and the initial fracture position with the variation of angle between the direction of the perforation channel and the preferred fracture plane. A complex and tortuous nearwell fracture geometry tends to be induced in conventional spiral perforations. With optimized direction of jet flow of the in-plane perforation, the initial fracture propagation trajectory directed toward the preferred fracture plane and reduced the tortuosity of near-wellbore. This will improve the efficiency of hydraulic fracturing stimulation.

\section{Conclusions}

(1) A three-dimensional coupled hydromechanical fracturing model is established to investigate the propagation of near-wellbore fracture geometry, together with a continuum-based damage mechanics constitutive relationship.

(2) Finite element program is developed and employed to analyze the impact of perforations on fracture geometry in horizontal wells. The model was validated against the analytical solutions and experimental results, the capability of modeling $3 \mathrm{D}$ nearwellbore fracture geometry and fracture propagations demonstrated.

(3) Perforation angle variations result in variable initiation pressure and complex fracturing pattern for horizontal wells. By increasing the stress interference effect among perforations and changing the direction, it benefits to lower the fracture initial pressure.

(4) Perforation has a further effect on the fracture geometry of near-wellbore region in horizontal wells.
Optimizing perforation parameters can direct the propagation of the initial fracture toward the preferred transverse fracture plane benefiting wellboreto-fracture connectivity. Consequently, it improves the efficiency of hydraulic fracturing stimulation.

\section{Data Availability}

The data used to support the findings of this study are available from the corresponding author upon request.

\section{Conflicts of Interest}

The authors declare that there are no potential conflicts of interest regarding the publication of this article.

\section{Acknowledgments}

This work was supported by the National Natural Science Foundation of China (NSFC) (No. 51304230), the Fundamental Research Funds for the Central Universities (16CX05001A), and the China Scholarship Council Fund (201706455025).

\section{References}

[1] G. E. King, "Thirty years of gas shale fracturing: what have we learned?" in Proceedings of the SPE Annual Technical Conference and Exhibition 2010, ATCE 2010, pp. 900-949, September 2010.

[2] M. Y. Soliman, J. Daal, and L. East, "Fracturing unconventional formations to enhance productivity," Journal of Natural Gas Science and Engineering, vol. 8, pp. 52-67, 2012.

[3] L. Behrmann and J. Elbel, "Effect of Perforations on Fracture Initiation," Journal of Petroleum Technology, vol. 43, no. 05, pp. 608-615, 2013.

[4] H. H. Abass, S. Hedayati, and D. L. Meadows, "Nonplanar fracture propagation from a horizontal wellbore: experimental 
study," SPE Production and Facilities, vol. 11, no. 3, pp. 133-137, 1996.

[5] L. A. Behrmann and K. G. Nolte, "Perforating requirements for fracture stimulations," SPE Drilling \& Completion, vol. 14, no. 4, pp. 228-234, 1999.

[6] R. van Ketterij and C. de Pater, "Impact of perforations on hydraulic fracture tortuosity," SPE Production \& Facilities, vol. 14, no. 02, pp. 117-130, 1999.

[7] B. Lecampion, J. Desroches, X. Weng, J. Burghardt, and J. E. Brown, "Can we engineer better multistage horizontal completions? evidence of the importance of near-wellbore fracture geometry from theory, lab and field experiments," in Proceedings of the SPE Hydraulic Fracturing Technology Conference 2015, pp. 539-557, February 2015.

[8] G. Waters and X. Weng, "The impact of geomechanics and perforations on hydraulic fracture initiation and complexity in horizontal well completions," in Proceedings of the SPE Annual Technical Conference and Exhibition, ATCE 2016, UAE, September 2016.

[9] H. Liu, F. Wang, Y. Wang, Y. Gao, and J. Cheng, "Oil well perforation technology: Status and prospects," Petroleum Exploration and Development, vol. 41, no. 6, pp. 798-804, 2014.

[10] S. H. Fallahzadeh, V. Rasouli, and M. Sarmadivaleh, "An investigation of hydraulic fracturing initiation and near-wellbore propagation from perforated boreholes in tight formations," Rock Mechanics and Rock Engineering, vol. 48, no. 2, pp. 573584, 2014.

[11] M. M. Hossain, M. K. Rahman, and S. S. Rahman, "Hydraulic fracture initiation and propagation: roles of wellbore trajectory, perforation and stress regimes," Journal of Petroleum Science and Engineering, vol. 27, no. 3-4, pp. 129-149, 2000.

[12] H. Zhu, J. Deng, X. Jin, L. Hu, and B. Luo, "Hydraulic fracture initiation and propagation from wellbore with oriented perforation," Rock Mechanics and Rock Engineering, vol. 48, no. 2, pp. 585-601, 2014.

[13] O. P. Alekseenko, D. I. Potapenko, S. G. Cherny, D. V. Esipov, D. S. Kuranakov, and V. N. Lapin, "3D modeling of fracture initiation from perforated noncemented wellbore," SPE Journal, vol. 18, no. 3, pp. 589-600, 2013.

[14] M. M. Hossain and M. K. Rahman, "Numerical simulation of complex fracture growth during tight reservoir stimulation by hydraulic fracturing," Journal of Petroleum Science and Engineering, vol. 60, no. 2, pp. 86-104, 2008.

[15] P. Papanastasiou and A. Zervos, "Three-dimensional stress analysis of a wellbore with perforations and a fracture," in Proceedings of the 1998 SPR/ISRM Rock Mechanics In Petroleum Engineering, EUROCK, pp. 347-355, July 1998.

[16] S. Cherny, V. Lapin, D. Kuranakov, and O. Alekseenko, “3D model of transversal fracture propagation from a cavity caused by Herschel-Bulkley fluid injection," International Journal of Fracture, vol. 212, no. 1, pp. 15-40, 2018.

[17] Q. Shan, Y. Jin, M. Chen, B. Hou, R. Zhang, and Y. Wu, "A new finite element method to predict the fracture initiation pressure," Journal of Natural Gas Science and Engineering, vol. 43, pp. 58-68, 2017.

[18] F. Zhang and M. Mack, "Modeling of hydraulic fracture initiation from perforation - Tunnels using the 3D lattice method," in Proceedings of the 50th US Rock Mechanics / Geomechanics Symposium 2016, pp. 854-860, USA, June 2016.

[19] E. Sarvaramini, M. B. Dusseault, and R. Gracie, "Characterizing the stimulated reservoir volume during hydraulic fracturingconnecting the pressure fall-off phase to the geomechanics of fracturing," Journal of Applied Mechanics, vol. 85, no. 10, Article ID 101006, 2018.

[20] B. Xu and R. C. K. Wong, "Coupled finite-element simulation of injection well testing in unconsolidated oil sands reservoir," International Journal for Numerical and Analytical Methods in Geomechanics, vol. 37, no. 18, pp. 3131-3149, 2013.

[21] S. Xue and Y. Yuan, "Sanding process and permeability change," Journal of Canadian Petroleum Technology, vol. 46, no. 04, 2007.

[22] S. Yin, M. B. Dusseault, and L. Rothenburg, "Coupled multiphase poroelastic analysis of reservoir depletion including surrounding strata," International Journal of Rock Mechanics and Mining Sciences, vol. 44, no. 5, pp. 758-766, 2007.

[23] C. A. Tang, L. G. Tham, P. K. K. Lee, T. H. Yang, and L. C. $\mathrm{Li}$, "Coupled analysis of flow, stress and damage (FSD) in rock failure," International Journal of Rock Mechanics and Mining Sciences, vol. 39, no. 4, pp. 477-489, 2002.

[24] A. Shojaei, A. Dahi Taleghani, and G. Li, "A continuum damage failure model for hydraulic fracturing of porous rocks," International Journal of Plasticity, vol. 59, pp. 199-212, 2014.

[25] E. Detournay and A. H.-D. Cheng, "Fundamentals of poroelasticity," in Analysis and Design Methods, pp. 113-171, Elsevier, 1993.

[26] W. C. Zhu and C. A. Tang, "Numerical simulation of Brazilian disk rock failure under static and dynamic loading," International Journal of Rock Mechanics and Mining Sciences, vol. 43, no. 2, pp. 236-252, 2006.

[27] R. W. Lewis and B. A. Schrefler, Finite Element Method in the Deformation and Consolidation of Porous Media, 1998.

[28] M. A. Biot, "General theory of three-dimensional consolidation," Journal of Applied Physics, vol. 12, no. 2, pp. 155-164, 1941.

[29] M. Ferronato, N. Castelletto, and G. Gambolati, "A fully coupled 3-D mixed finite element model of Biot consolidation," Journal of Computational Physics, vol. 229, no. 12, pp. 4813-4830, 2010. 


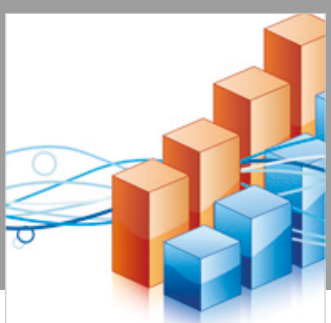

Advances in

Operations Research

\section{-n-m}
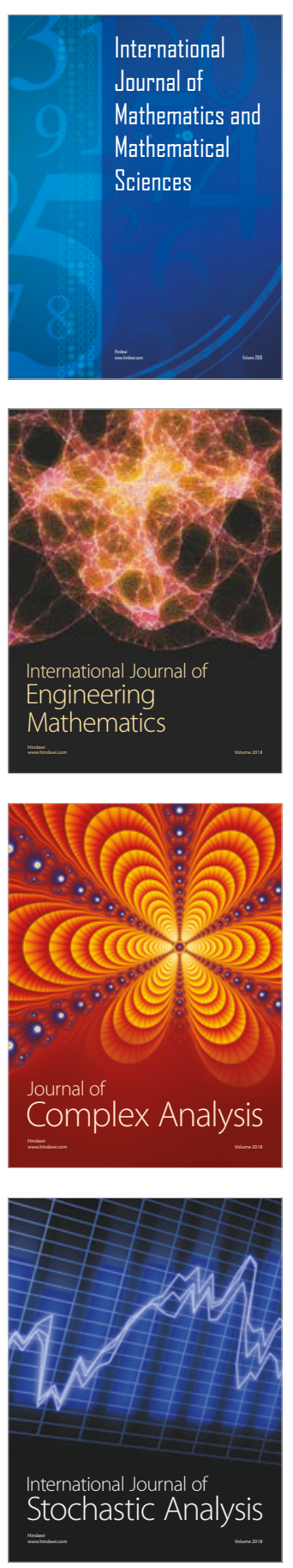
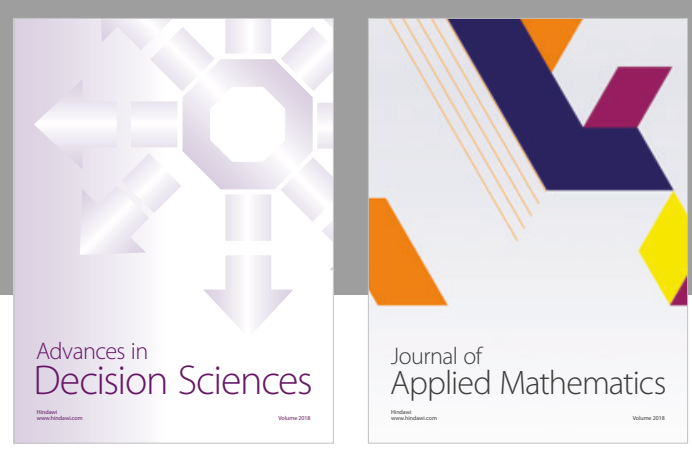

Journal of

Applied Mathematics
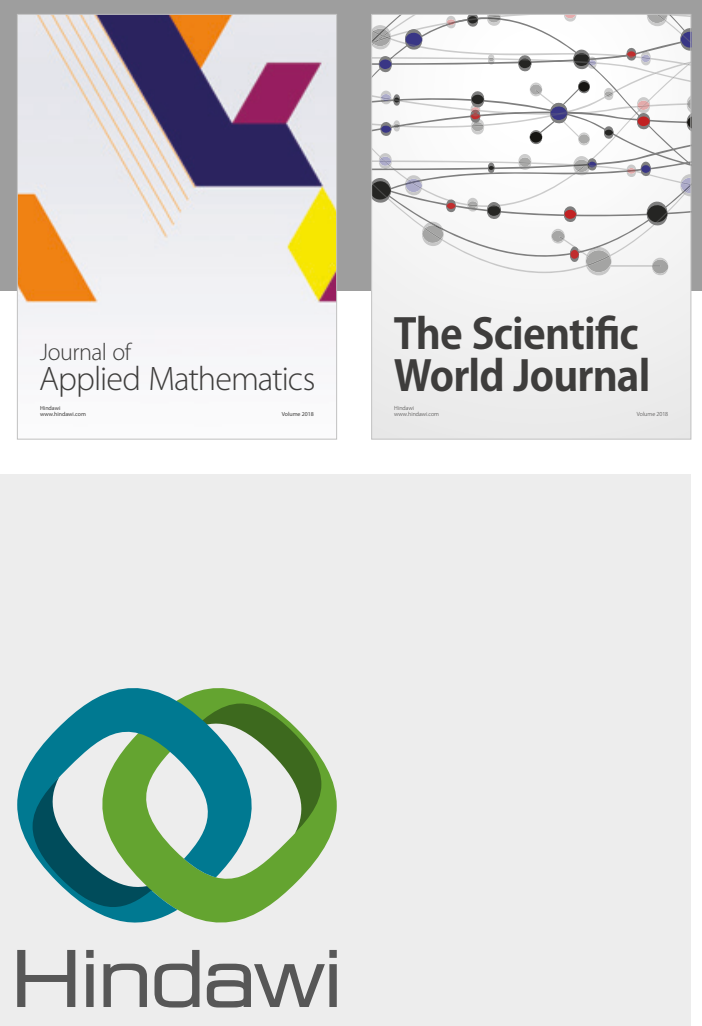

Submit your manuscripts at

www.hindawi.com

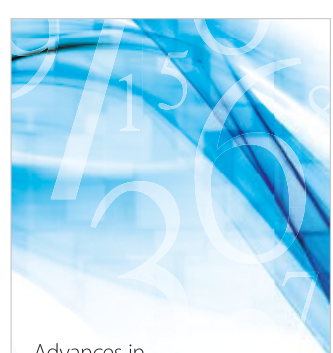

Advances in
Numerical Analysis
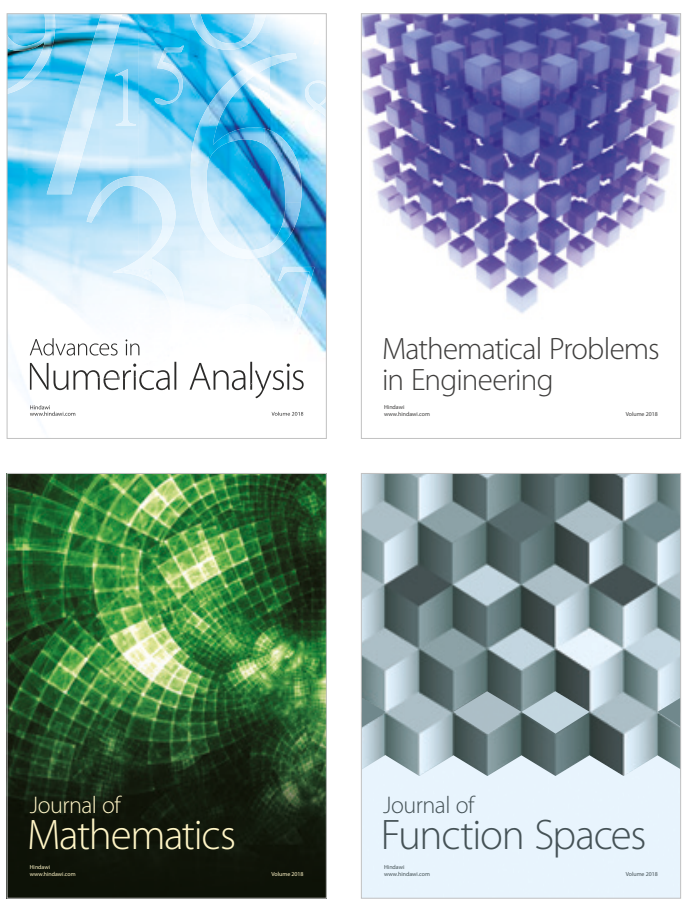

Mathematical Problems in Engineering

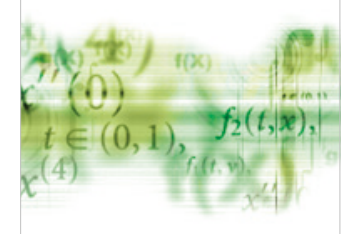

International Journal of

Differential Equations

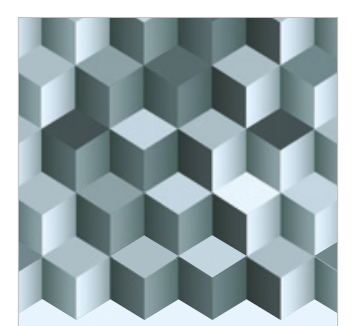

Journal of

Function Spaces

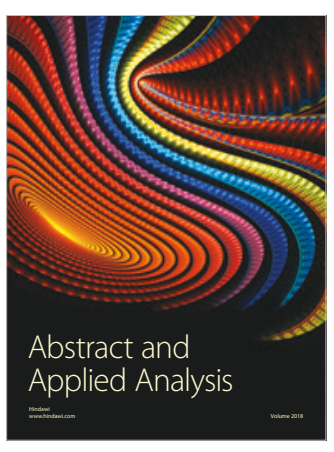

The Scientific

World Journal

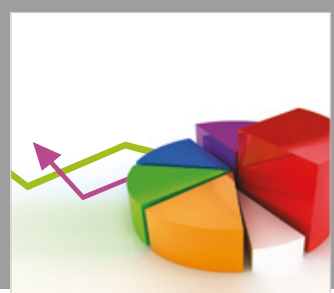

Journal of

Probability and Statistics
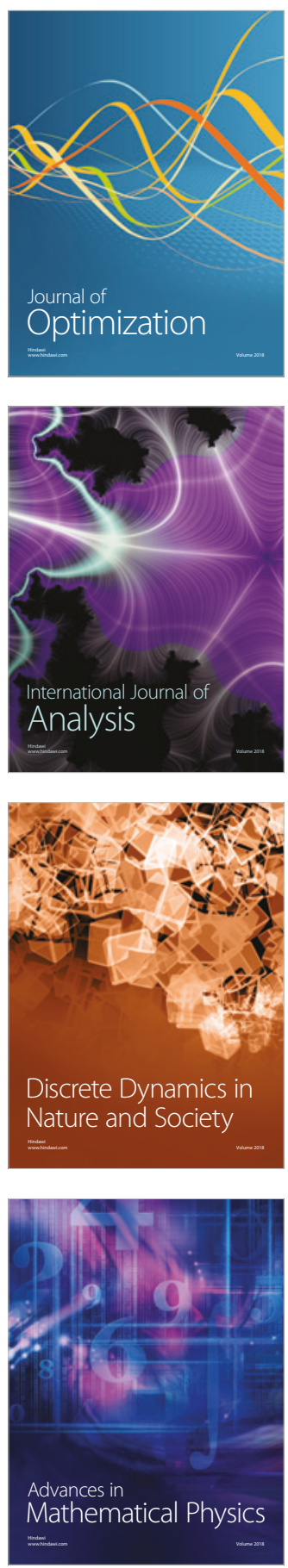